\title{
The Status of Teaching Translation at Gaza Universities: Analysis and New Insights
}

\author{
Dr. Mohammed El Haj Ahmed* \\ Assistant Professor of Translation, Head of the English Department, Islamic University of Gaza \\ *Corresponding Author: Dr. Mohammed El Haj Ahmed, Assistant Professor of Translation, Head of the \\ English Department, Islamic University of Gaza
}

\begin{abstract}
The purpose of this study is to evaluate the current status of teaching translation at Gaza Universities. Using the Descriptive-Analytic approach the researcher examined the current teaching practices including teaching courses, text books, teaching instructors and methods, and a remedial plan aimed at improving translation-training programmes and meeting the demands of the Palestinian labour market was suggested. Integrating theory and practice into translation classrooms, the suggested plan aims at providing new insights for translation instructors who should coordinate efforts with curriculum designers to meet the translation needs, skills and competences of their students.
\end{abstract}

Keywords: Current Teaching Practices, Gaza Universities, Remedial Plan, Status of Teaching Translation, Translation-Training Programmes

\section{INTRODUCTION}

Every translation activity has one or more specific purposes and whichever they may be, the main aim of translation is to serve as a cross-cultural bilingual communication vehicle among peoples. In the past few decades, this activity has developed because of rising international trade, increased migration, globalization, the recognition of linguistic minorities, and the expansion of mass media and technology. For this reason, the translator plays an important role as a bilingual or multi-lingual crosscultural transmitter of culture and truths by attempting to interpret concepts and speech in a variety of texts as faithfully and accurately as possible.

English is now a major international language and the demand for translation has steadily increased. Moreover, English is the language of instruction at local and international universities, which means that a large number of materials are translated into English as well as other languages including Arabic. However, the lack of qualified translators and the absence of effective and systematic training in translation theory have led to erroneous translations (El Haj Ahmed, 2009). In this regard, Masoud (1988: 10) is right when she says, "More often than not, new translators dive into translation work thinking that because they speak two languages, they are qualified for the task".

Masoud's statement makes it clear that translators entirely depend on their language competence to practice translation, a view which is also shared by Baker (2011: 3-4), who states:

"Translators need to develop an ability to stand back and reflect on what they do and how they do it. Like doctors and engineers, they have to prove to themselves as well as others that they are in control of what they do; that they do not just translate well because they have a 'flair' for translation, but rather because, like other professionals, they made a conscious effort to understand various aspects of their work."

The lack of language competence as perceived by Masoud and translation competence as perceived by Baker among Arab translators in general and Palestinian translators in particular has had negative impact on translators' performance when they join the labour market. Describing translation in the Arab world, El Shafei (2014:146), states that the "weakness in students' translation can in turn affect the quality of their preparation for [the] labour market, resulting from the lack of well-designed courses for translation". El Shafei's view was also shared by Gaber (2002) who states: 
"The main weakness lies in the fact that translation lacks an effective overall pedagogy because educators do not look sufficiently at professional needs, and consequently produce graduates who are not fully suited to the real world of professional translation."

In Palestine the demand for translation has increased very rapidly. According to El Fagawi (2000), this is due to the Palestinians' belief that English has become the language of international negotiation through which they can tell the world about their problem. This motivational interest in English and especially in translation increased after the Oslo Agreement between the Palestinians and the Israelis. As a result, Gaza and the West Bank have become a major focus of international media attention, with large numbers of journalists from all over the world visiting the area to cover the political situation. These journalists from all over the world are willing to listen to all Palestinians, including ordinary people in the street. At the same time, the Palestinian people have shown much interest in talking with these journalists about their painful experiences with the occupation. In most cases, journalistic delegations hire local translators and interpreters in order to facilitate their communication with ordinary people.

In addition to the need of translators and interpreters to convey the daily sufferings of the Palestinians living under the occupation to the international world, there is also a need for professional translators and interpreters in other fields such as law (court documents for expatriates) and government (Ministries of Interior, Tourism, etc.). With the expansion of the internet and social media many translators are working as freelance translators providing translations services online, something that needs to be taken into consideration by syllabus design specialists when designing translation coursers.

\subsection{Research Questions}

The study is specifically addressing the following two main questions:

- What is the current status of teaching translation at Gaza universities?

- How can the teaching of translation at Gaza local universities be improved?

\subsection{Justification of the Study}

A number of studies including Thawabteh (2009), Amer (2010), Atari (2012), Al Aqad (2017) El Haj Ahmed (2017), Abu- Ghararah (2015 and 2017), and Thawabteh and Shehab (2017) have discussed one aspect or another of the teaching translation situation at Arab universities. Unlike previous studies, the present study will focus on the current situation of teaching translation at Gaza universities and provide analysis and new insights. The findings of the study are intended to draw the attention of those specialists in the field of translator training to the actual situation of teaching translation at Gaza universities and suggest remedies to improve this situation.

\subsection{Significance of the Study}

Unlike the previous studies, the present study tries to diagnose the current situation of teaching translation at Gaza local universities with the aim of finding the proper solutions for the problems encountering translation trainers and trainees. The outcomes reached in this study will provide Arab universities in general and Palestinian universities in particular with some solutions for teaching translation.

\section{LITERATURE REVIEW}

The researcher has reviewed a number of previous studies done on teaching translation in the Arab world in general and in teaching translation in Palestine in particular. The studies reviewed by the researcher include:

Al Aqad's (2017) study focuses on the problems of teaching translation encountered by the students at Gaza Strip universities. The researcher believes that translation courses are taught simply because they have traditionally been part of the English curriculum of a bachelor degree. He also pointed out that translation courses in these universities have only had academic rather than professional goals. To improve the level of these translation courses the researcher proposes new solutions to improve teaching translation at university level in Gaza. 
Abu-Ghararah's (2017) study aims at evaluating the translation industry in Saudi Arabia in order to identify the professional contexts for which universities should be preparing translators. The study examines the types of translation organizations found in the country and investigates the demands of today's translation market in Saudi Arabia. The study has found that there is a huge gap between academic training and the requirements of the Saudi translation market. The study suggests that the training programmes need to be constructed specifically to meet the demands of the Saudi translation market.

Thawabteh and Shehab (2017) try to explore the status of professionally-oriented translation, curriculum-wise in Palestine as illustrated in two Palestinian universities offering MA in translation. Specifically, the study closely examines the course description of the courses offered by the two universities. The study shows that although most of the courses offered help graduates manage to get jobs, the curricula seem to fail to match the employability in the growing market place, as some courses at these universities, with a varying degree, are unrelated to the local job market. The researchers made suggestions in the hope of giving some advice to developers of academic postgraduate translation programmes in Palestine.

Atari's (2012) study seeks to engage scholars involved in translator training/translator education in a debate on the current state of affairs in most Arab university translator training programs. Specifically, the author highlighted the impediments to translator training at Arab universities including lack of complementarity in classroom teaching, mismatch between workplace expectations and translation teaching norms in academic settings, and opposed ideologies among translator trainers. The author presents some translation descriptors for teaching and assessment and two modules for training trainers and trainees.

Amer (2010) studied the problems encountering the teaching of translation at Gaza universities and the suggested solutions. The study focused on the learning/teaching outcomes of teaching translation in the English departments at Gaza local universities. The researcher found that the translation courses do not train students to pursue a professional career in translation, adding that translation classes in these universities have only had academic rather than professional goals. He suggested a new road map for improving teaching translation at university level.

Thawabteh's (2009) study aims at exploring the status of professionally-oriented translation versus the academisation of translation. Based on a case study of the Centre for Continuing Education's Welfare Online Translation Project, the study argues that translator training in the Occupied Palestinian Territories still lags behind most countries, although there have been some attempts to initiate translator training.

\section{MeTHOdOLOGY}

The study adopted the descriptive-analytic approach. The researcher described the current situation of teaching translation at Gaza universities and analyzed the different teaching practices including teaching courses, text books, teaching instructors and methods with the aim of diagnosing the difficulties encountering translation students and translator trainers and suggesting a remedial plan to improve the current situation.

\subsection{The Study Sample}

The present study is based on the analysis of teaching translation at Gaza universities. These universities include Al Aqsa University, the Islamic University of Gaza (IUG), Al Azhar University, Al Quds Open University and Gaza University. Except Gaza University which offers a BA in translation, the other four universities offer translation as part of the BA in English language and literature. The IUG however began an MA in translation in 2015 attracting a large number of students who inspire to join the translation market.

\section{The Current Situation of Translation in GaZa}

Working as a lecturer of translation for the last 8 years both at the BA and MA levels and taking the points of view of the lecturers of translation at Gaza universities into consideration (personal communication), the researcher came up with the following results: 


\subsection{Courses Offered at the Bachelor Degree}

Two translation courses are currently taught at most Gaza universities except the Islamic University (IUG) which has introduced a third module of translation for students at the Faculty of Arts as an elective module. However, Gaza University has recently started a BA programme in translation. This adds to the IUG's efforts in introducing a one year professional diploma in translation and interpreting for students seeking more experience and training in translation. In 2015 an MA in translation was introduced at the IUG with the aim of providing high-quality and professional training to students in a variety of texts and contexts. Indeed the programme has so far attracted a large number of students who inspire to join the market as professional translators and practitioners. Despite these attempts the level of translators and interpreters graduating from various higher education institutions in Gaza does not meet the required standards. A recent study (El Haj Ahmed, 2017) has stated that sworn translators who sat for exams administered by The Ministry of Justice in Gaza in the last few years showed that candidate' answers showed poor mastery of the mother tongue as well as of the target language (TL). The candidates also lacked the proper translation strategies as they had a strong tendency for literal translation.

\subsection{Translation Textbooks}

At the BA level not a single department has ever produced a textbook on translation, or even a guide for translation teaching or a manual for translators. Describing the current methodology being implemented in Gaza universities, Amer (2010: 3) states,

There is no clear teaching approach to be adopted. Students grapple with a trial and error task, trying to guess what the teacher has in mind, or on their lecture notes. They end up studying texts and the translation thereof, but learning very little about the craft of translation.

In their analysis of the postgraduate translation curriculum currently in use at Arab universities in general and Palestinian universities in particular, Thawabteh and Shehab (2017) clearly state:

A close look at the translation syllabi in the departments of English at Arab universities reveals how ad hoc the materials, testing, and grading systems of these syllabi are. Existing syllabi are inappropriate mainly due to the lack of qualified translation teachers, the absence of systematic teaching methods and the lack of appropriate textbooks.

The current situation of teaching translation as described by Amer and Thawabteh and Shehab will have devastating impact on graduates who enter the job market without receiving the proper translation training .

Looking at the textbooks used in teaching translation, the researcher has found that the following two text books are currently in use by translation instructors at Gaza universities, especially in the last few years:

Farghal, M. and Shunnaq, A (1999). Translation with Reference to English and Arabic: A Practical Guide.

\section{Organization:}

Unit One: Introducing the Main Concepts in Translation Studies

Unit Two: The Relevance of Grammar

Unit Three: Translating at the Text Level: Texts for General Purposes

Unit Four: Translating at the Text Level: Legal and Scientific Texts

Ghazala, H. (1995). Translation as Problems and Solutions. Organization:

Chapter One: Grammatical problems

Chapter Two: Lexical Problems

Chapter Three : Stylistic problems

Chapter Four: Phonological problems

The following is a list of the grammatical, lexical and stylistic translation problems as indicated in Table of Contents. 
Table1. Translation errors detected in Ghazala's study

\begin{tabular}{|l|l|l|}
\hline Grammatical problems & Lexical problems & Stylistic Problems \\
\hline Verb to "Be" & Literal translation & Formality vs. informality \\
Verb to "Do" & Synonymy & Fronting \\
Verb to "Have" & Polysemy and monosemy & Parallelism \\
Modals & Collocation & Ambiguity \\
Questions & Special fixed phrase: idioms and & Complex vs. simple style \\
Negation & proverbs & Short sentences \\
Nominal sentences vs. verbal sentences & Figurative language: translation & Long sentences \\
Word order & of metaphors & Passive vs. active \\
Personal pronouns & Technical translation: & Repetition and variation \\
Present participle vs. gerund & Arabicisation & Redundancy \\
Past participle & Proper names & Expressivity, context \\
Adjectives & Titles and \\
Tenses & Political establishments & Noadership \\
Conditional sentences & Geographical terms & Irony \\
Word classes & UN acronyms & Punctuation marks \\
Articles & Translation of culture & \\
Sentence connectors & & \\
\hline
\end{tabular}

As shown below the examples used by Ghazala are isolated and decontextualized. Most of the problems involved in his study are basic grammatical errors that novice translators might make.

- I I am a student. *) (أنا أكون طالباً) (p. 28).

- She is kind. *(هي تكون طيبة) (p. 28).

- The food was eaten. *) (كان أكل الطعام) (p. 30).

- The diplomat left for London. *(الدبلو ماسي غادر إلي لندن) (p. 49).

\subsection{Translation Instructors}

In the departments of English at Gaza universities, the two or three translation modules which are a major requirement of the degree of BA in English Language and Literature are taught by specialists in EFL and linguistics. Few of them have a qualification in translation. Most of them teach translation depending on their long experiences without possessing the right skills and competences required for this craft.

As far as the Arab World is concerned, Farghal has a similar view on that. He $(2000,39)$ points out that academic institutes in the Arab World "were caught off-guard in terms of the availability of competent translator trainers, with inevitable decision to assign the task of translation training to bilingual academics specializing in literature and/or linguistics." Those translation trainers, Farghal $(2000,39)$ adds "neither have sufficient theoretical background in translation studies nor they have the interest and/or motivation to familiarize themselves with translation studies as an adequatelyestablished sub-discipline of applied linguistics."

\subsection{Current Teaching Methods}

According to Munday (2016), throughout the very long history of studies trying to figure out the ideal method of translation, two approaches of translation studies emerged: the linguistic-oriented approaches of translation and the cultural-oriented descriptive approach. Most of the teaching methods currently in place at Gaza universities are linguistic-oriented. Language learning in secondary schools in the Gaza Strip had come to be dominated by what was known as the grammartranslation method. This method centered on the rote learning of the grammatical rules and structures of the foreign language. These rules were both practiced and tested by the translation of a series of usually unconnected and artificially constructed sentences exemplifying the structure(s) being studied. However, the grammar- translation method fell into increasing disrepute, particularly in many English-language countries, with the rise of the direct method or communicative approach to English language teaching in the 1960s and 1970s (ibid:14).

In his recent study (El Haj Ahmed, 2017), the researcher found that professional diploma translator students at the IUG committed a considerable number of lexical and textual problems when they translated a politically argumentative text from Arabic into English. The researcher attributed the high 
number of translation problems to translators' frequent use of linguistic-oriented approaches by translator trainers as well as translators' tendency for literal translation as they adhere to the source text word order without paying attention to the textual considerations of the TL.

\section{Remedial Plan}

In light of the previous discussion and the current situation of teaching translation at Gaza universities the researcher suggests a remedial plan that strikes a balance between linguistic-oriented approaches and cultural-oriented descriptive approaches. The suggested plan covers the following areas:

\subsection{Translation Courses}

In teaching English/Arabic/English translation tutors are required to make use of the following three classical textbooks on translation taking into consideration students' level:

\section{For beginner level}

5.1.1. In Other Words, by Mona Baker (2011): organisation

Based around equivalence:

Ch. 2: Equivalence at word level

Ch. 3: Equivalence above word level

Ch. 4: Grammatical equivalence

Ch. 5: Textual equivalence: thematic and information structures

Ch. 6: Textual equivalence: cohesion

Ch. 7: Pragmatic equivalence

Ch. 8: Beyond equivalence: ethics and morality

Examples and exercises are taken from various genres such as oral interpreting, website translation, and news/media translation.

\section{For intermediate level}

5.1.2. Thinking Arabic Translation, by James Dickins, Ian Higgins, and Sandor Hervey (2017): Organisation based around matrices, levels and ranks:

Ch. 1 Translation as a process

Ch. 2 Translation as a product

Ch. 3 Revising and editing TTs

Ch. 4 Cultural transposition

Ch. 5 Compensation

Ch. 6 Genre

Ch. 7 Denotative meaning

Ch. 8 Connotative meaning

Ch. 9 Phonic/graphic and prosodic issues

Ch. 10 Grammatical issues

Ch. 11 Parallelism

Ch. 12 Sentential issues

Ch. 13 Discourse and inter textual issues

Ch. 14 Metaphor

Ch. 15 Language variety: register, sociolect and dialect

Ch. 16 Introduction to technical translation

Ch. 17 Technical translation: botanical texts

Ch. 18 Technical translation: constitutional texts

Ch. 19 Technical translation: Islamic finance texts

Ch. 20 Translating consumer-oriented texts 
The theoretical part can be coupled with a tutorial focusing on collocations, idioms and fixed expressions, in a Top to Bottom Approach. The discussion on translation problems and strategies in such tutorial can encompass naturalness, shifts, style, register, markedness (eg., collocations in expressive texts). This is also followed by practical translation, with texts selected from different sources. For Arabic into English: texts may encompass online news articles and commentaries, personal documents, literature, advertisements, audiovisual translation, etc. For English into Arabic: in addition to the above, texts can include website translation, general (informative) technical, legal and medical/health texts.

\section{For Advanced level}

5.1.3. English-Arabic/Arabic-English Translation: A Practical Guide, by Basil Hatim (1997): Organisation based on text types:

a) Translating Legal Texts

Translating Legal Texts

The Preamble

The Legal Article

Initial and Concluding Legal Articles

b) Translating Detached Exposition

The Synopsis

The Summary

The Abstract

The Report (Person-oriented/Entity-oriented)

The News Report (Non-evaluative/Evaluative)

The Report (Formulaic/Executive/Personalized)

c) Translating Argumentation

The Less Involved Through-argument

The More Involved Through-argument

The Explicit Counter-argument

The Implicit Counter-argument

The Suppressed Counter-argument

This is also followed by practical translation and texts selected from different sources. For Arabic into English: texts may encompass online news articles and commentaries, personal documents, literature, advertisements, audiovisual translation, etc. For English into Arabic: in addition to the above, texts can include website translation, general (informative) technical, legal and medical/health texts.

\subsection{Class Organisation}

Class organisation is divided into:

- teacher-focused

- student-focused

- teacher- student-focused

\subsubsection{Teacher-focused}

Here the teacher leads discussion based on his/her own TT while students contribute as asked by teacher.

\subsubsection{Student-focused}

In student-focused, interaction will be on: 
- simple individual

- multiple individuals

- in groups:

a) Simple individual: Here one student writes up their version of TT on acetate / board or LCD projector connected to a PC.

b) Multiple individuals: Here a number of students write up bits of their versions of TT on acetate / board or LCD projector connected to a PC.

c) Groups: Here students work in groups to produce versions of TT / parts of TT.

\subsubsection{Teacher- and student-focused}

Here teacher puts up his/her TT on acetate/LCD projector connected to a PC, and students put up theirs on acetate / board or LCD projector connected to a PC.

\subsection{Student Class Preparation}

Student class preparation will be discussed under the following sub-headings:

- No pre-class work

$>$ Advantage: spontaneity of class work

$>$ Disadvantage: not much work is covered in class.

- Pre-class work on key elements

$>$ Advantage: students deal with key issues before class.

$>$ Disadvantage: class work can still be slow.

- Full pre-class translation

$>$ Advantage: students have full TT to discuss before class.

$>$ Disadvantage: students do not receive any pre-class guidance on particularly difficult elements.

- Pre-class work on key elements followed by full pre-class translation:

This includes the following steps:

$>$ Students receive ST (previous class).

$>$ Students receive 'key points' questions relating to source text (ST) (previous class).

$>$ After a few days, students receive proposed answers to 'key points' questions (via e-mail, Moodle, etc.).

$>$ Students produce full TT (for next class).

$>$ Students discuss their TTs with reference also to TT produced by teacher in class.

$>$ Teacher hands out teacher TT, with translation notes ('strategic decisions' and 'decisions of detail').

The above-mentioned steps are explained in more detail with examples to illustrate each step:

Step1 - Students receive ST (previous class)

\section{Practical1: Lexical item repetition and other forms of repetition}

\section{Assignment}

(i) Paying particular attention to lexical item repetition and other forms of repetition in the ST, discuss the strategic decisions that you have to take before starting detailed translation of the following text, and outline and justify the strategy you adopt. The ST is an academic book. The TT is also intended to be published as a book. You should take it that the TT audience will also be people with an academic interest in the subject (and therefore some specialist knowledge). 
(ii) Translate the text into English.

(iii) Explain the decisions of detail you made in producing your translation.

\section{Contextual information}

This extract is taken from the back cover blurb to نحن والآخر by ناصر الدين الأسد (1997). The book deals with relations between the Arab and Islamic worlds, and the West.

$S T$

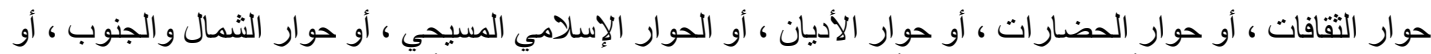

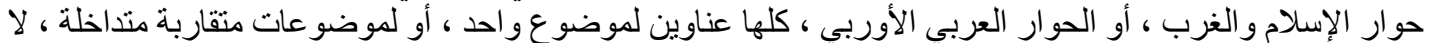

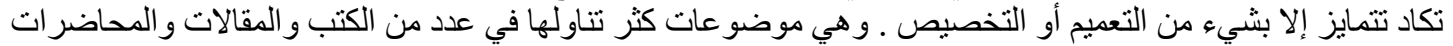

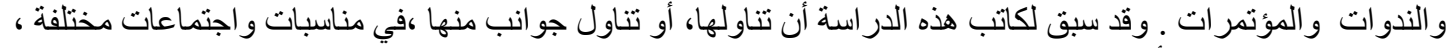

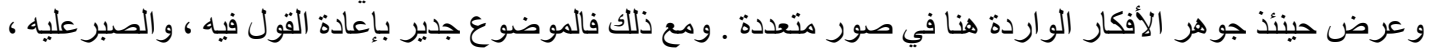

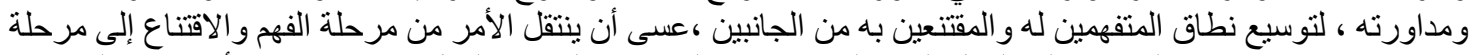

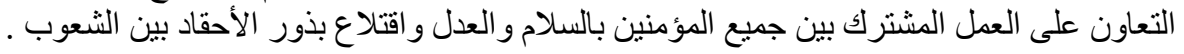

Step2 - Students receive 'key points' questions relating to ST (previous class)

\section{A. General (Strategic decision )}

1. What kind of style is the ST written in? What kind of style should the TT be written in?

\section{B. Special (Decision of detail)}

2. How can the following fairly literal translation of the start of this text be improved?

The dialogue/conversation/debate of/between cultures/ civilisations, or the dialogue between cultures/ civilizations, or the dialogue between religions, or the Muslim -Christian dialogue, or the dialogue between the north and the south, or the dialogue between Islam and the west, or the ArabEuropean dialogue, are all titles of /for one/a single topic/issue[...]

3. How can the phrase موضو عات متقاربة متداخلة be translated ?

4.What translation problems are posed by the phrase شيء من التعميم أو التخصيص ?

5. What translation problems are posed by the phrase مناسبات واجتماعات مختلفة منية

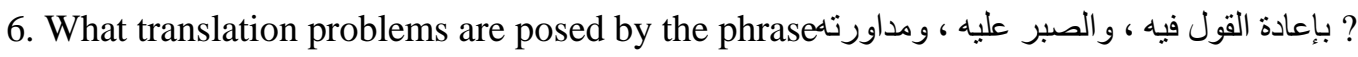

Step3 - Students receive proposed answers to 'key points' questions.

\section{A. General (Strategic decision )}

1. What kind of style is the ST written in? What kind of style should the TT be written in?

The ST is written in a formal, academic style. The TT should also be written in this style.

\section{B. Special (Decision of detail)}

2.How can the following fairly literal translation of the start of this text be improved?

The dialogue/conversation/debate of/between cultures/civilisations, or the dialogue between cultures/ civilizations, or the dialogue between religions, or the Muslim -Christian dialogue, or the dialogue between the north and the south, or the dialogue between Islam and the west, or the ArabEuropean dialogue, are all titles of /for one/a single topic/issue[...]

This fairly literal translation repeats the word "dialogue" seven times, just as the ST repeats the word حوار seven times. To improve the TT, the repetition of "dialogue" needs to be reduced. Ideally, "dialogue" should appear only once in this part of the TT. It is not easy to achieve this in English. However, it may help to begin with phrase such as "the notion of dialogue."

3. How can the phrase موضو عات متقاربة متداخلة be translated ?

The words متداخلة and are near- synonyms. A good way of dealing with such semantic repetition in Arabic is to use grammatical transposition, which Dickins et al 2017: 28 ) define as "the replacement or reinforcement of given parts of speech in the ST by other parts of speech in the TT." Hence the two words are grammatically transposed as "closely related" or "intimately related." 
Step 4 - Students produce full TT (for next class)

- Either:

$>$ Students bring this work with them to the class, for class discussion in comparison with TT produced by teacher.

- Or:

$>$ Teacher marks the work before the class, for further discussion in comparison with teacher TT in class

Step 5 - Students discuss their TTs with reference also to TT produced by teacher in class

The notions of dialogue ${ }^{1}$ between cultures, or civilisations, or religions, or between Islam and Christianity, or between North and South, or Islam and the West, or the Arab world and Europe, ${ }^{2}$ all $^{3}$ relate to ${ }^{4}$ a single topic, or, perhaps better, ${ }^{5}$ a group of intimately related ${ }^{6}$ topics which are only properly distinguishable in terms of their degree of specificity. ${ }^{7}$ These topics have been widely discussed in books, articles, lectures, seminars and conferences $;{ }^{8}$ I myself ${ }^{9}$ have dealt with them or with aspects of them in various meetings and on other occasions, ${ }^{10}$ and I have presented the fundamentals of the ideas discussed here in various forms. Nonetheless, this is an area which ${ }^{11}$ deserves further detailed consideration ${ }^{12}$ in order to make people better informed ${ }^{13}$ on all sides, ${ }^{14}$ in the hope of moving from the stage of information ${ }^{15}$ to that of co-operation between all those who believe in peace, justice, and the elimination of hatred between peoples. ${ }^{16}$

Step 6 - Teacher hands out teacher TT, with translation notes ('strategic decisions' and 'decisions of detail'), as shown below:

\section{i) Strategic decisions}

The translator needs to deal with the various forms of repetition which characterize this text in such a way that the TT reads like a piece of formal academic English writing. Accordingly, one might expect fairly long and well integrated TT sentences, as well as use of academic-oriented vocabulary. The translator also needs to make sure that the TT retains all significant features of the message content of the ST.

\section{ii) TT}

The notions of dialogue ${ }^{1}$ between cultures, or civilizations, or religions, or between Islam and Christianity, or between North and South, or Islam and the West, or the Arab world and Europe, ${ }^{2}$ all $^{3}$ relate to ${ }^{4}$ a single topic, or, perhaps better, ${ }^{5}$ a group of intimately related ${ }^{6}$ topics which are only properly distinguishable in terms of their degree of specificity. ${ }^{7}$ These topics have been widely discussed in books, articles, lectures, seminars and conferences ${ }^{8}{ }^{8}$ myself $f^{9}$ have dealt with them or with aspects of them in various meetings and on other occasions,${ }^{10}$ and I have presented the fundamentals of the ideas discussed here in various forms. Nonetheless, this is an area which ${ }^{11}$ deserves further detailed consideration ${ }^{12}$ in order to make people better informed ${ }^{13}$ on all sides, ${ }^{14}$ in the hope of moving from the stage of information ${ }^{15}$ to that of co-operation between all those who believe in peace, justice, and the elimination of hatred between peoples. ${ }^{16}$

\section{iii)Decisions of detail}

- حوار. The standard modern usage for this type of discussion, particularly between people of different religious or political beliefs, is 'dialogue'. It seems absolutely necessary for general TL stylistic reasons to reduce the seven occurrences of حوار to one occurrence of 'dialogue' in the TT. Unfortunately, this makes it impossible for denotative reasons to translate عناوين by 'term', which would otherwise be the obvious usage in this context. Thus, it is possible to say “"Dialogue between cultures", "Dialogue between civilizations" [...] are terms', or perhaps better "The terms "cultural dialogue", "civilization dialogue" $[\ldots]$ are [...]'. But it is not possible to say, "The terms "dialogue between cultures, civilizations [...]" are [...]": a listing which involves only one use of 'dialogue' does not involve discrete terms, but rather describes a number of different ideas, phenomena, or notions. We have used the term 'notions' at the beginning of the text, since this makes it plain to the reader from the outset why the subsequent long list is being presented. 
- It does not seem legitimate to reduce the number of list elements in the TT, since the function of listing here is not to give a general picture by providing specific instances (as is sometimes the case in Arabic), but to make the reader aware of the various different terms/notions currently in use with respect to the kinds of dialogue the author has in mind. A more concise translation would be obtained if adjectives could be used throughout to describe the kinds of dialogue in question. But this would sound very odd; e.g. 'The notions of cultural, civilizational, religious, Muslim-Christian, North-South, Islamic-Western, or Arab-European dialogue'. It is better if 'or' is placed between every element: 'The notions of cultural, or civilizational, or religious, or Muslim-Christian, or North-South, or Islamic-Western, or ArabEuropean dialogue'. However, this is still unsatisfactory: 'North-South' is not a genuine adjective phrase, and Islamic-Western is a strange pairing (Islam is a religion, and the West is a cultural region). In any case, the combination of length and extreme concision makes the complete phrase difficult to interpret. This is why we have used 'dialogue between' followed by a series of noun phrases, and divided the list into groups, using 'between' three times.

- 'All' is added to provide a kind of structural marker, reminding the reader that everything which precedes it is the subject of 'relate to'.

- In translating عناوين as 'relate to' we have chosen a phrase which would be coherent with the use of 'notions' at the beginning of the sentence and the immediately subsequent use of 'single topic'.

- We have added 'perhaps better' to make plain that the immediately preceding 'or' does not indicate a genuine choice: it is not that the notions of dialogue between cultures, civilizations, etc. relate either to a single topic, or to a group of intimately interrelated topics, but...

\section{RECOMMENDATIONS}

In the light of the previous discussion and analysis the researcher suggests the following:

- It is important to train translators, not only in the acquisition and command of languages and translation strategies and procedures, but also in specific knowledge areas and, what is equally important, in professional ethics.

- The high number of lexical, grammatical, textual errors encountered by students in my classes in particular and those reported by colleagues in their classes indicates that translators focus on accessing words rather than sentences or larger segments of texts. This in turn indicates that the translators have been using the bottom-up approach of processing the source texts (micro analysis rather than the top-down approach or the "macro" or "textual analysis." So translator trainers should pay attention to issues pertaining to the text analysis approach suggested by Hatim and Mason (1990) and Snell-Hornby (1995).

- Students' translation competence should strongly be emphasized in the training of Palestinian prospective translators. This includes his/her familiarity with different translation techniques and strategies such as the use of cultural or functional equivalent, synonymy, transposition, modulation, compensation, reduction and expansion or amplification. Other translation competences include reliable, competent output under pressure; self-awareness; subject expertise; research competence; fluency in L1 and L2; and an understanding of text type and genre appropriate style/register and conventions.

- To a great extent, the quality of translation will depend on the quality of the translator, i.e. on her/his knowledge, skills, training, cultural background, expertise, and even mood.!

- Universities in Gaza are required to recruit MA and PhD specialists in translation to teach translation courses in order to meet the rising needs for qualified translators in local and regional markets.

- Students should be aware of the theory of translation and guiding principles in the translation process, including, analysis of source text, its context of situation (register), genre (eg, academic abstract), text-type (e.g., argumentative, expository, expressive), discourse (the attitudinal component, the agenda, the ideological statement that a text makes), stylistic features (e.g., writer's idiosyncracies, presupposition of target recipients' knowledge, inter textuality, tenor, etc.). 
- The number of translation courses should increase from 2-3 to 4-5 courses as this additional number will expose students to a variety of teaching practices covering a wide range of texts.

- Issues such as translation and ideology, postcolonial studies, the use of technology in translation, etc. should be incorporated in the Palestinian translation syllabus.

- The findings of this study are intended to draw the attention of those specialists in the field of translation training and syllabus design to the urgent teaching of these topics given the significant role the translator plays in this globalized world.

- Due to the absence of an official register listing approved translators and interpreters, the study calls for the setting up of a professional body that contains all certified translators and documents the field, keeping translators and interpreters abreast of the new developments.

- Developing a curriculum in translation should be responsive to local, regional and international translation industry demands, and thus it might contribute to sustainable development in the Palestine translation industry.

- Information technology-based courses should be given more attention and developed so as to keep abreast of today's rapidly technological developments, since these courses might qualify graduates to cross various geographical borders to compete globally with peer translators.

\section{REFERENCES}

[1] Abu-Ghararah, B. (2017). The Gap between Translator Training and the Translation Industry in Saudi Arabia. Arab World English Journal for Translation \& Literary Studies, 1 (4), 107 -118.

[2] Abu-Ghararah, B. (2015). The Availability and Use of Technology and Learning Resources in Translation. Arab World English Journal. Special Issue on CALL. 81 - 90.

[3] Al Aqad, M. (2017) Challenges and Suggested Solutions of Teaching Translation at Gaza Strip Universities (Palestine). Arabic Language, Literature \& Culture. 2(2), 34-39

[4] Amer, W. (2010) Teaching Translation at Gaza Universities: Problems and Solutions. Refereed Papers of The First National Conference: Improving TEFL Methods \& Practices at Palestinian Universities, Al Quds Open University.

[5] Atari, O. (2012) Impediments to Translator Training at Arab Universities: Proposal for Change. Arab World English Journal. 3(1), 103-127.

[6] Baker, M. (2011). In Other Words: A Course book on Translation. London and New York: Routledge.

[7] Dickins, J., Hervey, S. and Higgins, I. (2017). Thinking Arabic Translation: A Course in Translation Method: Arabic to English. London and New York: Routledge.

[8] El Fagawi, I. (2000). A Proposal for a Self-Directed Programme of English Language for $3^{r}$ Intermediate Level Students in the Gaza Strip, Currently Using the 'Welcome to English' Course Book. MA Thesis. Heriot Watt University, Edinburgh.

[9] El Haj Ahmed, M. (2009). Lexical, Cultural and Grammatical Translation Problems Encountered by Palestinian EFL Learners at the Islamic University of Gaza, Palestine. PhD Thesis, The University of Salford.

[10] _ (2017). Lexical and Textual Translation Problems Encountered by Palestinian Professional Diploma Students at the Islamic University of Gaza, Journal of Humanities Research, Islamic University Gaza, 25 (1) 1-13.

[11] El Shafei, N. (2014). Implementing Professional Approach Within a Translation Course to Sharpen the Student/Translator's Practical Skills for Demands of the Labor Market. International Journal of Applied Linguistics and English Literature, (3) 2.

[12] Farghal, M.(2000). The Training of Student Translators. Turjuman 9 (1): 39-40.

[13] Farghal, M. and Shunnaq, A (1999). Translation with Reference to English and Arabic: A Practical Guide. Jordan: Dar Al Hilal for Translation.

[14] Gaber, M. (2002). A Skeleton in Closet: Teaching Translation in Egyptian National Universities. Translation Journal, 6 (1).

[15] Ghazala, H. (1995). Translation as Problems and Solutions. Beirut: Dar wa Maktabat Al-Hilal.

[16] Hatim, B. (1997) English-Arabic/Arabic-English Translation: A Practical Guide. London, Saqi Books.

[17] Hatim, B. and Mason, I. (1990). Discourse and the Translator. London and New York: Longman.

[18] Masoud, M. (1988). Translate to Communicate: A Guide for Translators. Elgin III, USA: David C. Cook Foundation. 
[19] Munday, J. (2016). Introducing Translation Studies: Theories and Applications. Fourth Edition. London and New York: Routledge.

[20] Newmark, P. (1988). Approaches to Translation. Hertfordshire: Prentice Hall.

[21] Snell-Hornby, M. (1995) Translation Studies: An Integrated Approach, Revised Edition. Amsterdam, John. Benjamins.

[22] Thawabteh, M. (2009) Apropos Translator Training Aggro: A Case Study of the Centre for Continuing Education. The Journal of Specialised Translation, (12), 166-179

[23] Thawabteh, M. \& Shehab, K.(2017 ) Post-graduate Translation Curriculum and Employability: The Case of Palestinian Universities. Research Journal Studies about Language, (30), 29-41.

\section{AUTHORS' BIOGRAPHY}

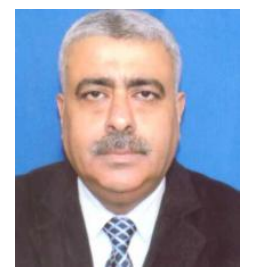

Dr. Mohammed El Haj Ahmed is an assistant professor of English language and translation at the Islamic University of Gaza. He obtained his BA in English language and literature at the Islamic University of Gaza, Palestine in 1988, his MA in Applied Linguistics at the University of Khartoum in 1995, and his Ph.D. in Translation Studies at the University of Salford, UK, in 2009. Since 1997 Dr. El Haj Ahmed has been a staff member at the English Department teaching Linguistics and Translation at the BA and MA levels.He has published several papers on translation in local and international journals. He has also supervised many MA theses and Professional Diploma Translation projects. He is currently working as the head of the English Department.

Citation: Dr. Mohammed El Haj Ahmed. "The Status of Teaching Translation at Gaza Universities: Analysis and New Insights " International Journal on Studies in English Language and Literature (IJSELL), vol 7, no. 1, 2019, pp. 1-13. doi: http://dx.doi.org/10.20431/2347 -3134.0701001.

Copyright: (C) 2019 Authors. This is an open-access article distributed under the terms of the Creative Commons Attribution License, which permits unrestricted use, distribution, and reproduction in any medium, provided the original author and source are credited. 